\title{
Glucose and Lactate Biosensors Prepared by a Layer-by-Layer Deposition of Concanavalin A and Mannose-Labeled Enzymes: Electrochemical Response in the Presence of Electron Mediators
}

\author{
Yuka KoBAYAshi, Tomonori Hoshi, and Jun-ichi AnZAI* \\ Graduate School of Pharmaceutical Sciences, Tohoku University, Aramaki, Aoba-ku, Sendai 980-8578, Japan. \\ Received November 20, 2000; accepted February 14, 2001
}

\begin{abstract}
An electrochemical response of glucose and lactate biosensors which were prepared by coating a platinum electrode with a thin film composed of concanavalin A and mannose-labeled glucose oxidase (GOx) or lactate oxidase (LOx) was evaluated in the presence of ferrocene derivatives as electron mediator. Both glucose and lactate biosensors showed catalytic current to glucose and lactate, respectively, in cyclic voltammetry, suggesting that the ferrocene derivatives can mediate electron transport smoothly from the reduced forms of GOx and LOx in the thin films to the electrode. Among the three kinds of ferrocene derivatives used, ferrocenylmethanol was found to be the most suitable electron mediator because of its low oxidation potential. The glucose and lactate sensors gave useful calibration graphs, in which higher detection limits were reached as compared with those observed when the sensors were operated in the absence of electron mediator.
\end{abstract}

Key words enzyme multilayer film; biosensor; electron mediator

Enzyme biosensors have been widely studied because of their usefulness in bioanalytical science and technology. ${ }^{1,2)}$ In this context, we have developed high-performance glucose and lactate sensors using enzyme multilayer films which were prepared by a layer-by-layer deposition of monomolecular layers of avidin and biotin-labeled glucose oxidase (GOx) and lactate oxidase (LOx). ${ }^{3-5)}$ The output current of the multilayer film-modified biosensors can be controlled precisely by regulating the number of enzyme layers in the multilayer films; the size of the response current is proportional to the number of enzyme layers. ${ }^{3-5)}$ It was also possible to eliminate ascorbate interference by immobilizing ascorbate oxidase simultaneously in the GOx and LOx multilayer films. $\left.{ }^{6}\right)$ Thus, the enzyme multilayer films prepared by taking advantage of a strong affinity between avidin and biotin were quite useful for improving performance characteristics of enzyme biosensors.

We recently reported another protocol to prepare enzyme multilayer films by means of the biological interaction between concanavalin $\mathrm{A}(\mathrm{Con} \mathrm{A})$ and mannose. ${ }^{7,8)} \mathrm{Con} \mathrm{A}$ is a lectin protein (molecular weight; $c a$. 104000) and is known to contain four identical binding sites to $\alpha$-D-mannose. ${ }^{9)}$ Con A and mannose-labeled GOx or LOx were deposited alternately on the surface of a platinum $(\mathrm{Pt})$ electrode by immersing the electrode in the solutions of Con A and enzymes alternately, to fabricate the multilayer film-modified enzyme sensors. After this simple treatment, the enzymes were built into the multilayer films composed of monomolecular layers of Con A and enzymes on the electrode surface through the biological affinity between Con A and mannose. The enzyme/Con A multilayer-modified electrodes thus prepared could be used to determine glucose and lactate, where the electric current was originating from the electrochemical oxidation of hydrogen peroxide generated through the enzyme reactions (Eqs. 1, 2).

$$
\begin{aligned}
& \text { glucose }+\mathrm{O}_{2} \stackrel{\text { GOx }}{\longrightarrow} \text { gluconolactone }+\mathrm{H}_{2} \mathrm{O}_{2} \\
& \text { lactate }+\mathrm{O}_{2} \stackrel{\text { LOx }}{\longrightarrow} \text { pyruvate }+\mathrm{H}_{2} \mathrm{O}_{2}
\end{aligned}
$$

In the present paper, as an alternative protocol for the op- eration of the enzyme sensors, a cyclic voltammetric response of the sensors is evaluated in the presence of ferrocene derivatives as electron mediator.

\section{Experimental}

GOx (EC 1.1.3.4, from Aspergillus niger, Sigma, St. Louis, U.S.A.), LOx (EC 1.1.3.2, from Pediococcus species, Boehringer Mannheim, Germany), and Con A (from Jack bean, Vector Lab., U.S.A.) were used as received. $\alpha$ D-Mannopyranosylphenylisothiocyanate (MPITC) was purchased from Sigma Co. (St. Louis, U.S.A.). All other reagents were of the highest grade available and were used without further purification.

Preparation of Mannose-Labeled Enzyme Mannose-labeled GOx and LOx were prepared as follows: $1 \mathrm{mg}$ enzyme and $0.5 \mathrm{mg}$ MPITC were dissolved in $0.1 \mathrm{M} \mathrm{NaHCO}_{3}$ solution $(0.5 \mathrm{ml})$, and the solution was stirred for $2 \mathrm{~h}$ at $c a .20^{\circ} \mathrm{C}$. The unreacted MPITC was removed from the reaction mixture by centrifugal filtration. Several residues of mannose were introduced on the surface of the enzyme.

Preparation of Enzyme Multilayer-Modified Electrode A Pt disk electrode (diameter: $3 \mathrm{~mm}$ ) was used throughout. The surface of the electrode was polished thoroughly with alumina powder and rinsed with distilled water before use. The Pt electrode was immersed in a Con A solution $\left(100 \mu \mathrm{g} \mathrm{ml}^{-1}\right.$ phosphate buffered saline (PBS)) for $20 \mathrm{~min}$ at room temperature to deposit the first Con A layer on the electrode surface and washed with PBS to remove any weakly adsorbed Con A. The Con A-modified electrode was then immersed in a mannose-labeled enzyme solution (100 $\left.\mu \mathrm{g} \mathrm{ml}^{-1} \mathrm{PBS}\right)$ for $20 \mathrm{~min}$ to immobilize the enzyme on the Con A surface through Con A/mannose complexation. To deposit the second layer of Con A and enzyme, the enzyme-modified electrode was treated similarly with the Con A and enzyme solutions. The same procedure was repeated to deposit further enzyme layers. The formation of the layer-by-layer structure of the multilayer films is based on the facts that Con A contains four binding sites per molecule and that several residues of mannose moieties are introduced on the surface of the enzymes. The procedure for constructing the enzyme layer is shown schematically in Fig. 1. The spectroscopic and microgravimetric characterization of the multilayer films was reported previously. ${ }^{7,8)}$

Electrochemical Measurement of the Sensor The electrochemical response of the enzyme-modified electrodes was measured using a conventional three-electrode system. The working electrode was the Con A/enzyme-modified electrode. $\mathrm{An} \mathrm{Ag}-\mathrm{AgCl}$ electrode with a liquid junction of $3.3 \mathrm{M} \mathrm{KCl}$ saturated with $\mathrm{AgCl}$ and a Pt wire were used as the reference and auxiliary electrodes, respectively. A $0.1 \mathrm{M}$ phosphate buffer $(\mathrm{pH}$ 6.8) was used for the measurements. Before measuring cyclic voltammogram (CV), dissolved oxygen was removed from the sample solution by introducing nitrogen $\left(\mathrm{N}_{2}\right)$ gas for $10-15 \mathrm{~min}$, and the $\mathrm{CV}$ was performed under $\mathrm{N}_{2}$ atmosphere. 


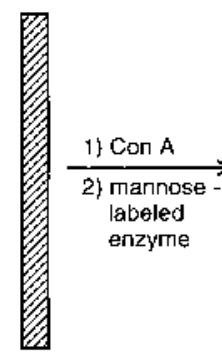

: Con A
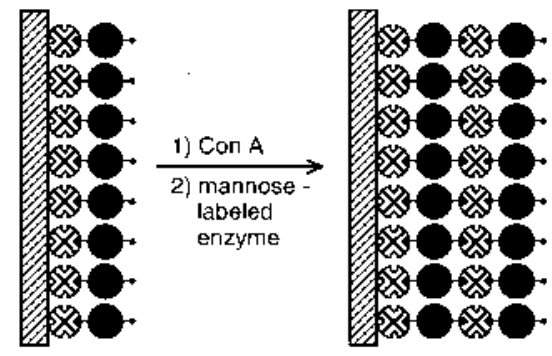

: mannose-labeled enzyme

Fig. 1. A Schematic Illustration of a Layer-by-Layer Deposition of Con A and Mannose-Labeled Enzyme on the Electrode Surface

\section{Results and Discussion}

We studied response characteristics of the sensors in the presence of ferrocene derivatives in the sample solution as synthetic mediators which can mediate electron transfer between enzyme and electrode. Figure 2 shows CVs of $0.5 \mathrm{~mm}$ ferrocenecarboxylic acid $(\mathrm{Fc}-\mathrm{COOH})$, ferrocenylmethanol $\left(\mathrm{Fc}-\mathrm{CH}_{2} \mathrm{OH}\right)$, and (ferrocenylmethyl)trimethylammonium bromide $\left(\mathrm{Fc}-\mathrm{CH}_{2} \mathrm{NMe}_{3}\right)$ (Fig. 3) recorded on the GOx/Con A multilayer-modified $\mathrm{Pt}$ electrode in the presence and absence of glucose. The ferrocene derivatives gave well defined reversible redox waves in the absence of glucose, showing that the ferrocene derivatives can penetrate the enzyme multilayer films smoothly to reach the electrode surface. ${ }^{10)}$ On the other hand, in the presence of $90 \mathrm{~mm}$ glucose, the oxidation peak current $\left(i_{\mathrm{p}}\right)$ was enhanced significantly. This would be caused by the fact that, upon addition of glucose, the concentration of the reduced form of ferrocene derivatives was enhanced in the $\mathrm{GOx} / \mathrm{Con}$ A film through the reaction cycle shown in Fig. $4 .{ }^{11)}$ In other words, the ferrocene derivatives mediate effectively electron transfer from the reduced form of GOx (or $\mathrm{GOx}-\mathrm{FADH}_{2}$ ) to the Pt electrode as illustrated in Fig. 4. Among the mediators tested, the catalytic current of $\mathrm{Fc}-\mathrm{COOH}$ was smaller than the other mediators. This is probably due to the electrostatic repulsion between $\mathrm{Fc}-\mathrm{COO}^{-}$anion and the negative charges in the film originating from Con $\mathrm{A}$ and GOx, because the reaction was carried out at $\mathrm{pH} 6.8$ where Con A and GOx should be negatively charged. A similar CV behavior was observed for the LOx multilayer-modified electrode in the presence of lactate. Thus, for both GOx and LOx multilayer-modified electrodes, the ferrocene derivatives can successfully mediate electron transfer between the enzymes in the multilayer films and electrode.

The oxidation waves of the ferrocene derivatives in $\mathrm{CV}$ were observed at $c a$. $+0.35 \mathrm{~V}$ for $\mathrm{Fc}-\mathrm{COOH}, c a .+0.25 \mathrm{~V}$ for $\mathrm{Fc}-\mathrm{CH}_{2} \mathrm{OH}$, and $c a$. $+0.45 \mathrm{~V}$ for $\mathrm{Fc}-\mathrm{CH}_{2} \mathrm{MMe}_{3}$. The biosensors should be operated at low electrode potential to circumvent the possible interference caused by oxidizable compounds such as ascorbic acid and uric acid. ${ }^{12)}$ From this viewpoint, $\mathrm{Fc}-\mathrm{CH}_{2} \mathrm{OH}$ is considered to be the most suitable electron mediator for practical use for the determination of glucose or lactate.

The $i_{\mathrm{p}}$ value in $\mathrm{CV}$ would depend on the surface concentration of GOx or LOx on the electrode in the presence of excess amounts of glucose or lactate, because the heterogeneous electron transfer rate between the ferrocene derivatives
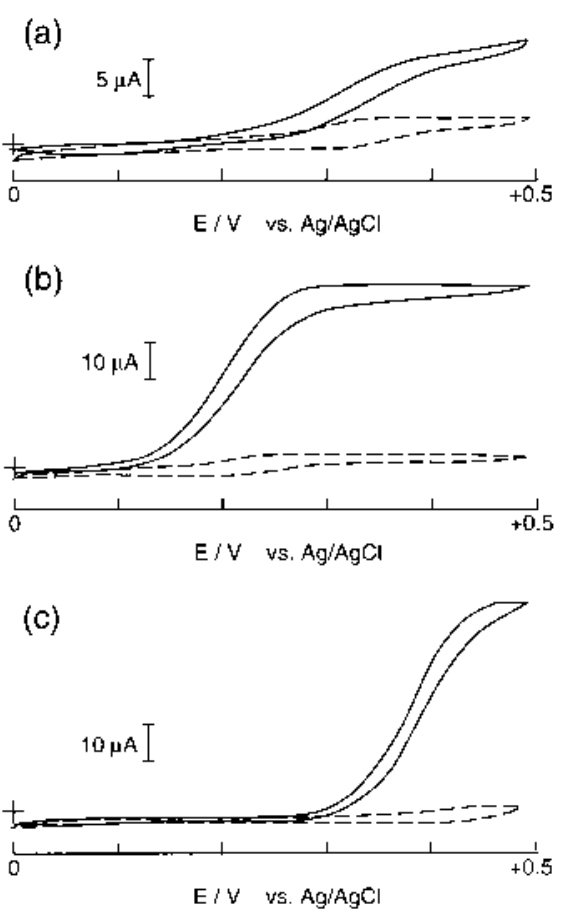

Fig. 2. Typical CVs of $\mathrm{Fc}-\mathrm{COOH}(\mathrm{a}), \mathrm{Fc}-\mathrm{CH}_{2} \mathrm{OH}$ (b), and $\mathrm{Fc}-\mathrm{CH}_{2} \mathrm{NMe}_{3}$ (c) on the GOx Multilayer Film-Modified Pt Electrode in the Presence (and Absence (---) of Glucose ( $90 \mathrm{~mm}$ )

The multilayer film was composed of $10 \mathrm{Con} \mathrm{A} / \mathrm{GOx}$ layers. The concentration of ferrocene derivatives: $0.5 \mathrm{~mm}$. Scan rate in $\mathrm{CV}: 10 \mathrm{mV} / \mathrm{s}$.

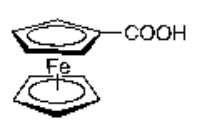

$\mathrm{Fc}-\mathrm{COOH}$

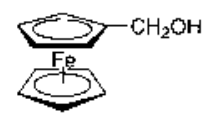

$\mathrm{Fc}-\mathrm{CH}_{2} \mathrm{OH}$

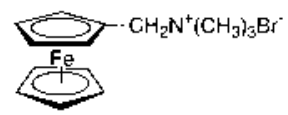

$\mathrm{Fc}-\mathrm{CH}_{2} \mathrm{NMe}_{3}$
Fig. 3. Chemical Structures of $\mathrm{Fc}-\mathrm{COOH}, \mathrm{Fc}-\mathrm{CH}_{2} \mathrm{OH}$, and $\mathrm{Fc}-\mathrm{CH}_{2} \mathrm{NMe}_{3}$

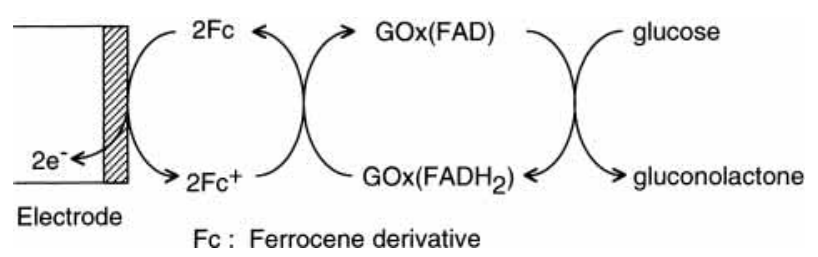

Fig. 4. Ferrocene-Mediated Electroenzymatic Reaction Cycle of GOx

and electrode is much faster than the rate of redox reaction of oxidized form of the ferrocene derivatives and reduced GOx or LOx. ${ }^{13)}$ Therefore, it is interesting to evaluate the relationship between the $i_{\mathrm{p}}$ value and the number of enzyme layers of the multilayer-modified electrodes. Figure 5 plots $i_{\mathrm{p}}$ values for the glucose and lactate sensors as a function of the number of enzyme layers. For both sensors, the $i_{\mathrm{p}}$ values increased linearly with increasing number of enzyme layers. The linear dependence of $i_{\mathrm{p}}$ on the number of enzyme layers suggests that a constant amount of enzyme is immobilized by each deposition to form an ordered layer-by-layer structure and that all enzyme molecules are catalytically active throughout the multilayer. ${ }^{13)}$ This data suggests also that the multilayer films are rather porous so that the electron mediators diffuse smoothly in the multilayer films. We have re- 


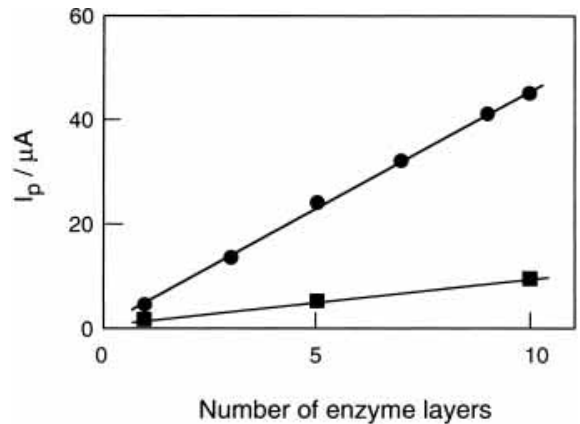

Fig. 5. The Peak Current $\left(i_{\mathrm{p}}\right)$ of $\mathrm{CV}$ for $0.5 \mathrm{~mm} \mathrm{Fc}-\mathrm{CH}_{2} \mathrm{OH}$ on Con A/GOx Multilayer (- - ) and Con A/LOx Multilayer-Modified Electrode (- - ) as a Function of the Number of Enzyme Layers

The concentrations of glucose and lactate were 90 and $30 \mathrm{~mm}$, respectively. Scan rate in $\mathrm{CV}: 10 \mathrm{mV} / \mathrm{s}$.
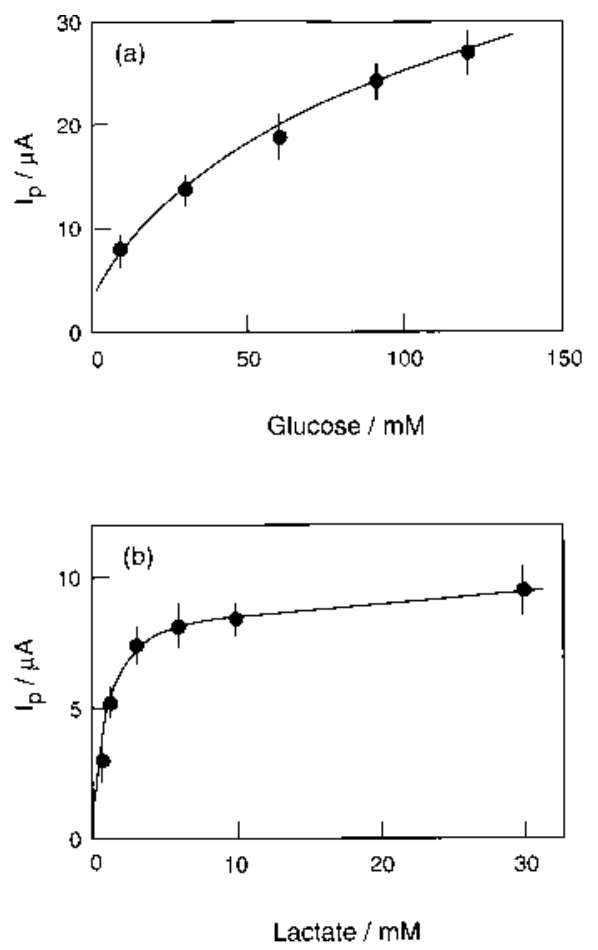

Fig. 6. Calibration Graphs for Glucose Sensor (a) and Lactate Sensor (b) The sensors were modified with 7 layers of $\mathrm{Con} \mathrm{A} / \mathrm{GOx}$ film and 10 layers of Con $\mathrm{A} / \mathrm{LOx}$ film. The concentration of $\mathrm{Fc}-\mathrm{CH}_{2} \mathrm{OH}: 0.5 \mathrm{~mm}$. Scan rate in $\mathrm{CV}: 10 \mathrm{mV} / \mathrm{s}$.

ported previously that, in the absence of electron mediator, the magnitude of the amperometric response of the GOx and LOx multilayer film-modified electrodes depends linearly on the number of enzyme layers, where the electric current was measured under a constant electrode potential at $+0.6 \mathrm{~V}$ to detect enzymatically generated hydrogen peroxide. ${ }^{7,8)}$ The $\mathrm{CV}$ data in Fig. 5 is in line with the results obtained from the amperometric measurements in the absence of electron mediator.

To evaluate usefulness of the multilayer-modified electrodes as enzyme biosensors, the $i_{\mathrm{p}}$ values were plotted $v$. the concentration of glucose and lactate in the presence of $0.5 \mathrm{~mm} \mathrm{Fc}-\mathrm{CH}_{2} \mathrm{OH}$ (Fig. 6). We observed separately that, when the concentration of $\mathrm{Fc}-\mathrm{CH}_{2} \mathrm{OH}$ was lower than $0.5 \mathrm{~mm}$, the $i_{\mathrm{p}}$ values did not depend on the concentration of glucose but were determined by the concentration of
$\mathrm{Fc}-\mathrm{CH}_{2} \mathrm{OH}$. Under such conditions, redox reaction between oxidized ferrocene and the reduced form of the enzymes may determine the rate of the entire reaction cycle in Fig. 4. Therefore, we employed $0.5 \mathrm{mM} \mathrm{Fc}-\mathrm{CH}_{2} \mathrm{OH}$ to obtain a glucose- or lactate-dependent response. The glucose sensor showed a useful calibration graph up to more than $50 \mathrm{~mm}$ glucose. The higher detection limit of the glucose sensor is enhanced $c a$. 5-times as compared with the detection limit observed when the sensor was operated at $+0.6 \mathrm{~V}$ in the absence of electron mediator. The enhanced dynamic range of the glucose sensor may be useful for measuring the blood glucose level of diabetics, in view of the fact that normal and diabetic blood levels of glucose are ca. 5-20 mM. As for the lactate sensor, the higher detection limit is $c a .3 \mathrm{~mm}$, which is slightly higher than the detection limit observed when the sensor was operated in the absence of electron mediator.

The catalytic activities of the GOX/Con A and LOx/Con A films were reduced to $c a$. $50 \%$ of the original activities after two months and after two weeks, respectively. The film-modified electrodes were stored in the working buffer in a refrigerator.

\section{Conclusions}

The glucose and lactate sensors prepared using multilayer thin films composed of Con A and GOx or LOx functioned as enzyme biosensors in the presence of ferrocene derivatives as electron mediator. $\mathrm{Fc}-\mathrm{COOH}, \mathrm{Fc}-\mathrm{CH}_{2} \mathrm{OH}$ and $\mathrm{Fc}-$ $\mathrm{CH}_{2} \mathrm{NMe}_{3}$ mediated electron transfer successfully from the reduced forms of GOx and LOx to electrode. The magnitude of catalytic current of the sensors increased proportionally with increasing number of enzyme layers (or the loading of enzymes on the electrode). The multilayer film-modified biosensors may be useful for determining a high concentration of glucose and lactate.

Acknowledgements The present work was supported in part by Grantsin-Aid (Nos. 11480252 and 1543) from the Ministry of Education, Science, Sports and Culture of Japan.

\section{References}

1) Rogers K. R., Mulchandani A., Zhou W., "Biosensor and Chemical Sensor Technology," American Chemical Society, Washington, DC., 1995.

2) Janata J., Josowicz M., Vanysek P., Devaney D. M., Anal. Chem., 70, 179R-208R (1998).

3) Anzai J., Hoshi T., Osa T., Trends Anal. Chem., 13, 205-210 (1994).

4) Hoshi T., Anzai J., Osa T., Anal. Chem., 67, 770_774 (1995).

5) Chen Q., Kobayashi Y., Takeshita H., Hoshi T., Anzai J., Electroanalysis, 10, 94-97 (1998).

6) Anzai J., Takeshita H., Kobayashi Y., Osa T., Hoshi T., Anal. Chem., 70, 811-817 (1998).

7) Anzai J., Kobayashi Y., Nakamura N., J. Chem. Soc., Perkin Trans. 2, 1998, 461-462.

8) Anzai J., Kobayashi Y., Langmuir, 16, 2851-2856 (2000).

9) Becker J. W., Reeke G. N. Jr., Cunningham B. A., Edelman G. M., Nature (London), 259, 406-409 (1976).

10) We observed that the peak currents in the CVs were suppressed very slightly (less than $10 \%$ ) for the enzyme-modified electrodes as compared with the response on unmodified Pt electrode.

11) Cass A. E. G., Davis G., Francis G. D., Hill H. A. O., Aston W. J., Higgins I. J., Plotkin E. V., Scott L. D. L., Turner A. P. F., Anal. Chem., 56, 667-671 (1984).

12) Maidan R., Heller A., Anal. Chem., 64, 2889-2896 (1992).

13) Bourdillon C., Demaille C., Gueris J., Moiroux J., Savéant J. M., J. Am. Chem. Soc., 115, 12264-12269 (1993). 